\title{
History of the Creation of BESM: The First Computer of S.A. Lebedev Institute of Precise Mechanics and Computer Engineering
}

\author{
Vera B. Karpova ${ }^{1}$ and Leonid E. Karpov ${ }^{2}$ \\ ${ }^{1}$ Lebedev Institute of Precise Mechanics and Computer Engineering, Russian Academy of \\ Sciences, Manager of the Institute History Museum \\ kotre@mail.ru \\ ${ }^{2}$ Institute for System Programming, Russian Academy of Sciences, Senior System Analyst \\ mak@ispras.ru
}

\begin{abstract}
Some aspects of the history of the first Soviet computer development are described. The idea of this work was offered by Sergey Lebedev who formulated the principles, wrote a plan and suggested the structure of the computer which was named BESM - Fast Electronic Calculating Machine. Some new documents are presented - a working notebook with Lebedev's handwritten notes and a plan of a preliminary project draft development. BESM computer became the first in the long series of Soviet computers built under the leadership of Lebedev. It also was used as a prototype of the first Chinese computer built with the help of Soviet engineers.
\end{abstract}

Keywords: digital computer history, Darmstadt conference, Chinese computer.

\section{Introduction}

Institute of Precise Mechanics and Computer Engineering of the USSR Academy of Sciences (AS USSR) was established in 1948. At that time, two types of calculating devices (forerunners of modern digital electronic computers) were under development. They were the analog computers (mechanical or electronic but not digital) and the relay computers (digital but electromechanical, not electronic). Both the principles of computer design and computers themselves were introduced in the USSR by Sergey Lebedev (1902-74), shown in Figure 1. One could say that it was predetermined in the very beginning of his scientific activity. In 1933, Lebedev and Prof. Petr Zhdanov published their joint monograph "Stability of parallel functioning of electrical systems" [9]. His thesis for a doctoral degree was also devoted to this topic. Almost every project of Lebedev was built on enormous amount of mathematical calculations. Quite logically, that brought up the idea of some facility that could automate those routine operations. That idea was in his mind permanently.

To calculate parameters of the power transmission line from the river Volga to Moscow (several thousand miles) he managed to install highly automated device constructed of powerful coils and capacitors. That device mathematically modeled the real transmission line. Implementation of that model (in fact - a special calculating 
device) helped to perform all the calculations and produced a complete set of project documents for that unique line. This work was partly repeated by Lebedev during the World War II when he was engaged in design of stabilizing system for tank gun and an automatic targeting device for aircraft torpedo. Those devices could perform both basic arithmetic operations, and differentiation and integration; yet they were still analog devices. Nevertheless, there are evidences that Lebedev was interested in digital computing devices long before the war.

During 1948 and 1949 Lebedev formulated basic principles of electronic calculating machine architecture that were very similar to Janosh (John) von Neumann's principles (see Figure 2), who described his conception in a secret report in 1945. This work became known in the Soviet Union much later; all of Lebedev's work (both theoretical and practical) was carried on independently. Lebedev emphasised the following requirements:

○ A computers must have arithmetic device, memory, control and input/output units;

- Both the program written in machine codes and the numbers should be stored in the same memory;

- Binary notation should be used for representation numbers and instructions;

- All calculations should be performed automatically according to the (stored in memory) program;

- Logical operations should be performedin addition to arithmetic operations;

○ Computer memory should have a hierarchic structure.

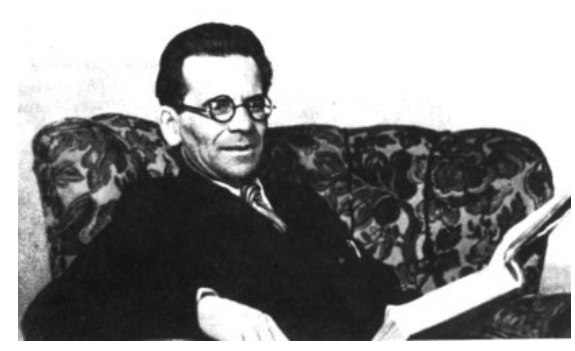

Fig. 1. S.A. Lebedev (1950s)

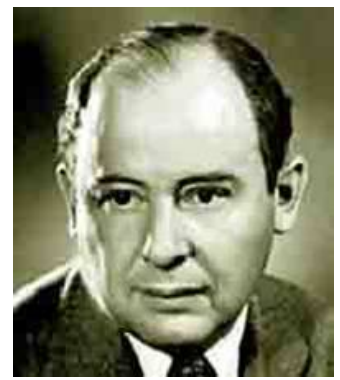

Fig. 2. Janosh (John) von Neumann

In 1945, Lebedev was elected a member of the Ukraine Academy of Sciences (AS). There he started his work on the electronic calculating machine MESM (Russian abbreviation of "Model Electronnoy Stchetnoy Mashiny" - Model of Electronic Calculating Machine), in 1947[5]. His actual intention was to begin researches with creating just an operating model but, considering the (post war) financial difficulties of the Academy, such "luxury" was impossible. However, MESM was quite operable computer. Design of storage device and other basic units (including general computer structure) was finished by the end of 1949. The first half of the 1950s was dedicated to manufacturing and adjusting of the machine components. 


\section{BESM and Lebedev's Technical Notes}

On 16 March of 1950, Lebedev was appointed a director of the Laboratory No. 1 at the Moscow Institute of Precise Mechanics and Computer Engineering (now - IPMCE AS Russia). He continued his work with the Kiev MESM team in parallel. He was invited to the IPMCE by M.A. Lavrentev, than its director, who offered Lebedev the position of chief designer of a new computer called the BESM ("Bystrodeystvuyushchaya Electronnaya Stchetnaya Mashina" - Fast Electronic Calculating Machine). Soon after that MESM got the name of the Small Electronic Calculating Machine (in Russian - Malaya Electronnaya Stchetnaya Mashina): Again MESM, but no longer the "Model".

Lebedev brought his own project draft from Kiev, where he represented his view on the BESM architecture. One of the IPMCE best designers, Petr Golovistikov (shown in Figure 3), in [8] wrote the following:

"There exists a legend that Lebedev drew the whole BESM scheme on his "Kazbek" cigarette boxes or on separate paper sheets. That's wrong. His project description consisted of several thick notebooks. One could see there the detailed schemes and timing diagrams, including many different versions of different operations production."

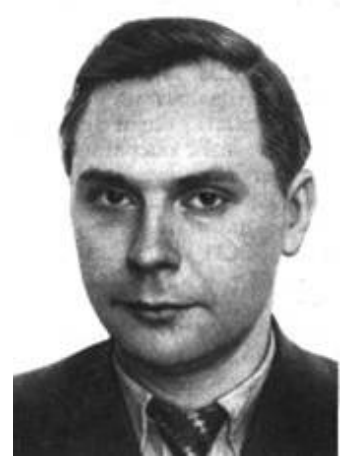

Fig. 3. Petr P. Golovistikov (the 1950s)

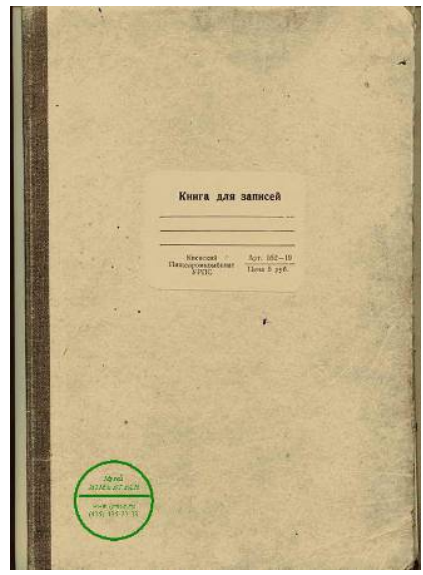

Fig. 4. Cover of Lebedev's working notebook

V.B. Karpova, collaborator of the IPMCE museum, identified among other IPMCE documents one of those notebooks (see Figure 4), which had been purchased in Kiev. The notebook consists of 100 grid sheets and is filled out in Lebedev's own hand. Among the titles that are in the notebook, we can see the following.

07.07.50: External memory management (magnetic recording).

09.07.50: Sending data from magnetic tape to the drum.

12.07.50: To consider the model version, which includes common elements for instructions and numbers with one control switch that works on 4 clock pulses (not 3).

16.07.50: Hardware and program controlled data transfer from tape to drum.

Choosing number of bits for the machine word.

Choosing the number of bits for the model with parallel number input. 
21.07.50: Translating from binary to decimal presentation using the computer.

Operations.

23.07.50: Magnetic tape control.

04.08.50: Possibility and reasonability of parallel code input and trigger sells memory implementation.

08.08.50: $\quad$ Sending data from the drum to internal memory.

12.08.50: Multiplication with sequential code input.

Flow-chart of executive unit.

Flow-chart of dynamic memory on electro-acoustic tubes.

Adjusting the IM (instruction management) from CCU (central control unit).

Organizational of work.

Deliverables.

Finally.Calculating the remainder absolute value.

Multiplication with $2 \mathrm{n}$ bits output.

Addition with $2 \mathrm{n}$ bits.

Developing the method of special operations production.

Addition with exponent blocking.

One-address instruction variant.

Reading of this notebook helps us to follow the entire process of gradual (though very fast) understanding of the future computer structure. The first date marked in the notebook is 7 July 1950, when Lebedev was already working on both projects bringing the MESM model to operational mode and developing the first "real" computer BESM. The last date (12 August 1950) is denoted on page 46 (see Figure 5). The subsequent notes are not dated. This means that it took only one month to fill the half of the notebook. Obviously the second half was filled out by the end of the summer of 1950. During this period, Lebedev developed basic units of the future computer and the algorithms of performing (producing as it is written in the notebook) of basic operations: addition, multiplication, division.
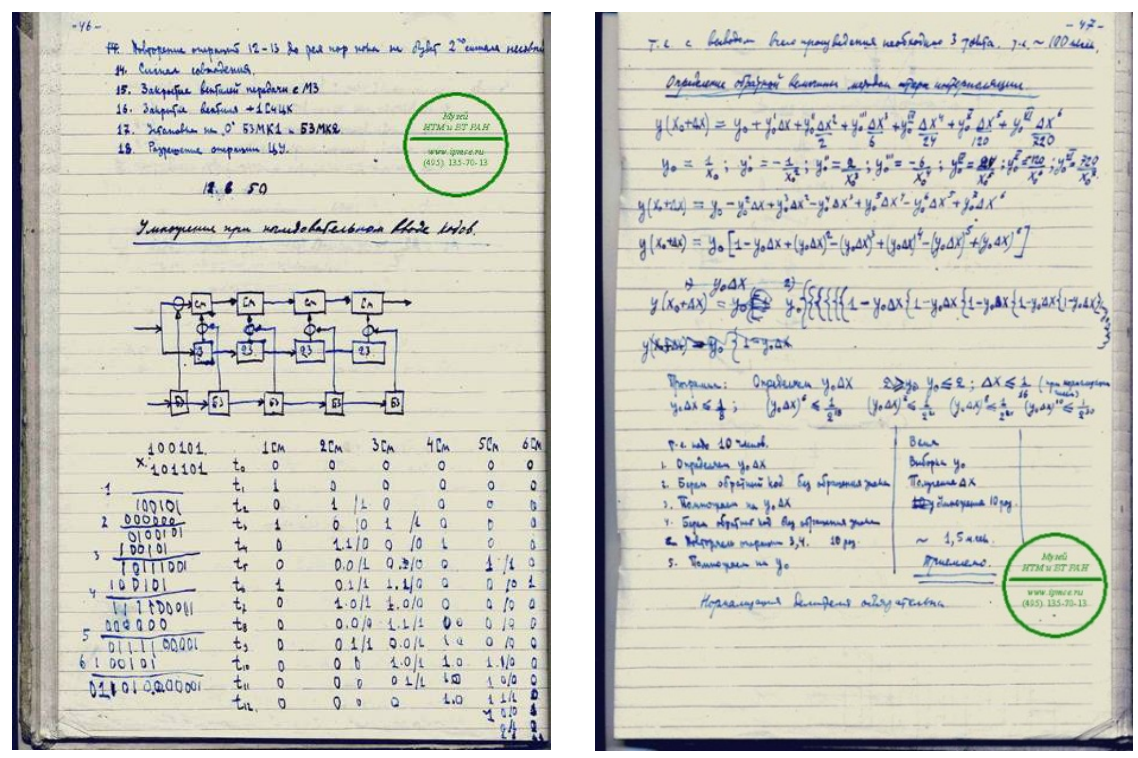

Fig. 5. Pages 46 and 47 of Lebedev's working notebook 
It was necessary to calculate everything, even the length of magnetic tapes, intended to be external memory. The calculations like this may be seen on pages 6 and 7 (see Figure 6). As a result, the total tape length was estimated (approximately 200 meters) and the total time of data transfer from tape to drum (about 20 minutes). Moreover, here the remark is, "The time is acceptable ".
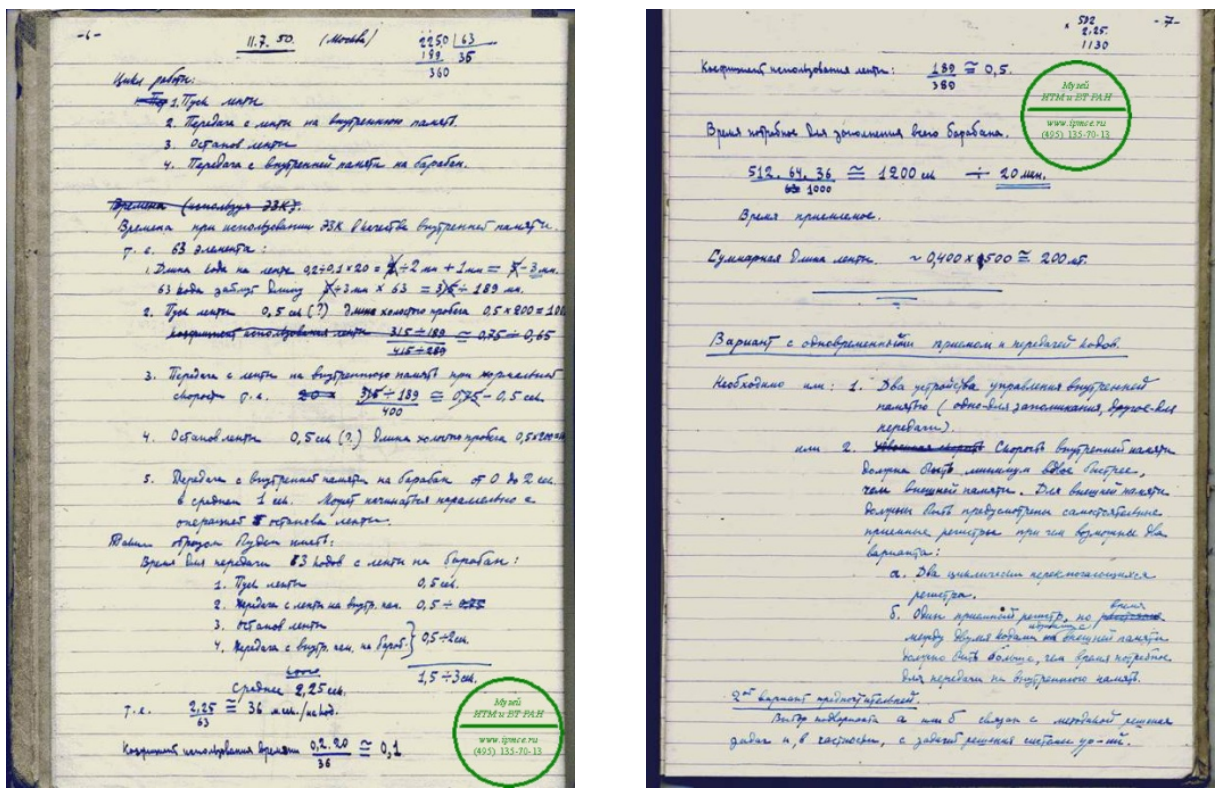

Fig. 6. Pages 6 and 7 of Lebedev's working notebook

Lebedev described all operations in details, at the same time he tried to estimate the time needed to perform those operations, trying to find answers to the basic questions of the starting period of every new computer design - is it worth implementing this or that operation, what would be the overall performance of the computer? For example, on page 47 (see Figure 5) after calculating the time of performing the operation of getting the value of $1 / x$ (with precision not less than $2^{-30}$ ) there is the result written: 1,5 milliseconds and the resolution reads: "Acceptable". Pages 84 and 85 are of special interest (see Figure 7).

These two pages contain notes which are not about technical details (see Figures 8 and 9): they are focused on organizational principles of the big computer project. The notes were definitely made during the preparation for a meeting with government authorities, who were the key persons for the new computer development. In the notes, we can see the concerns with which both development teams (Kiev team and Moscow team) encountered. The number of problems is not small but the conclusion is quiet simple - with a real help for the project, it is possible to build the computer by the second half of 1952. It is surprising but the terms were met. 

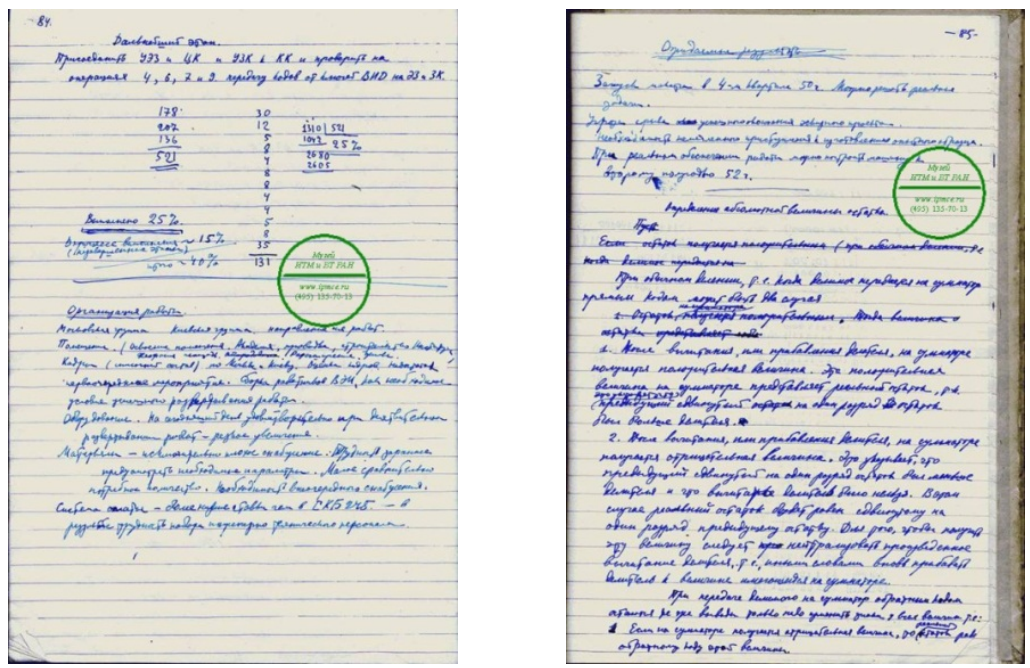

Fig. 7. Pages 84 and 85 of Lebedev's working notebook

\section{Oprasugarme pasata.}

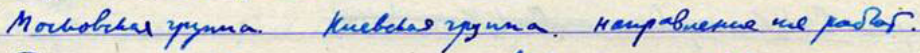

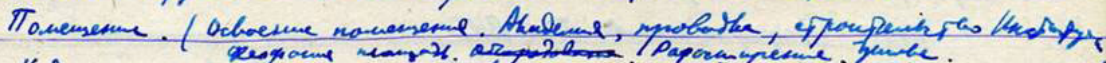

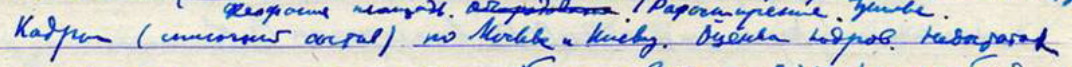

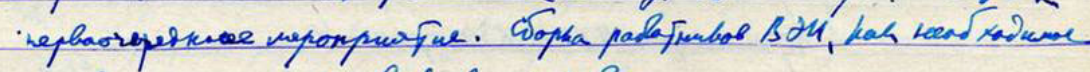

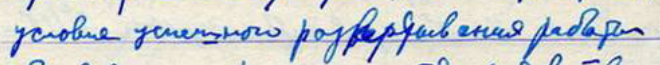

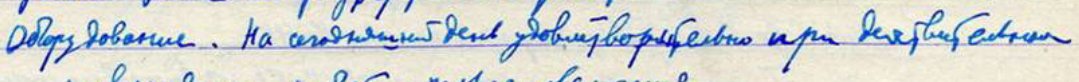
paghepposanm porlaf - pegleve ybeminerme.

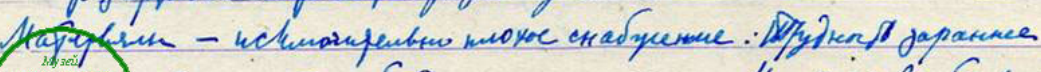

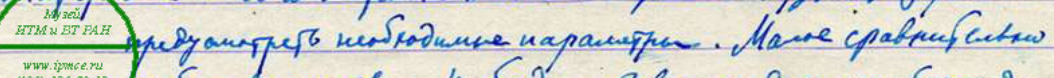

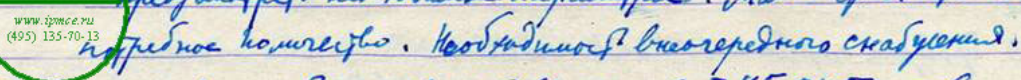

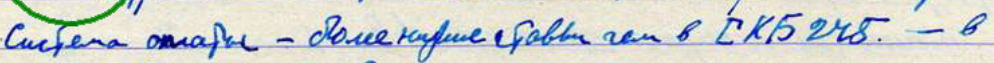

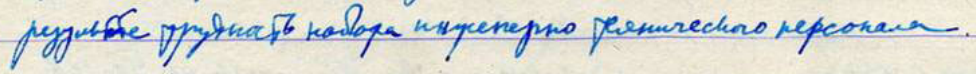

Fig. 8. Lebedev's working notebook fragment devoted to the organizational problems of two development teams 


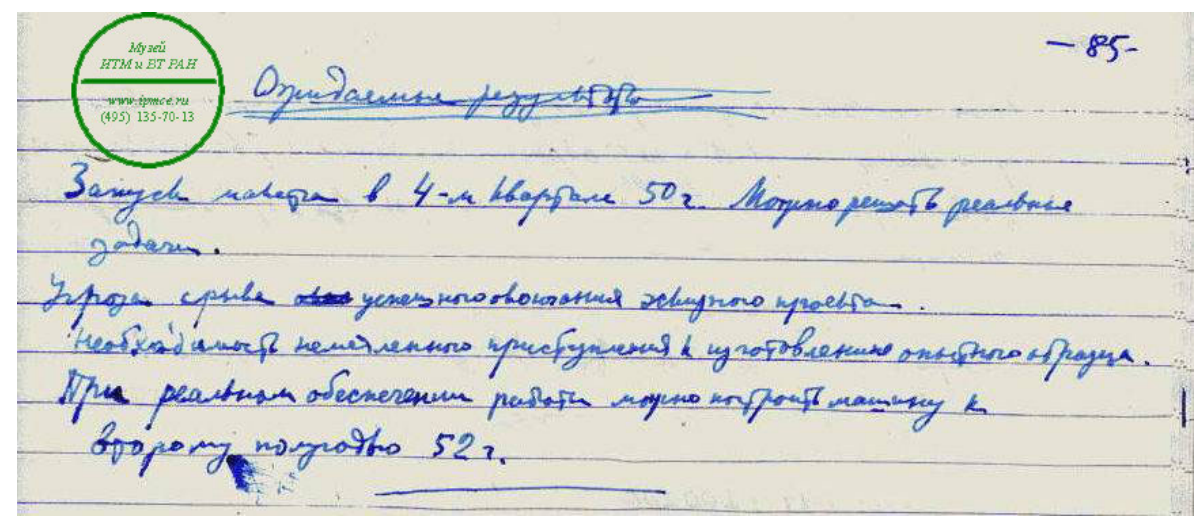

Fig. 9. Lebedev's working notebook fragment devoted to the BESM project expectations

\section{Lebedev's Organizational Notes}

V.B. Karpova made the following decryption of the organizational notes and project plans written by Lebedev.

Organization of work (page № 84 of Lebedev's notebook).

- Moscow team. Kiev team. Project directions.

- Offices (preparing the offices. Academy, electrical wires, building the Institute

- Theophania (location of the Kiev laboratory). Space. Increasing offices. Apartments)

- Personnel (the list) in Moscow and Kiev. Personnel estimation. Need for more.

- Immediate task. Gathering employees from Electrical Institute (VEI-AllUnion Electrotechnical Institute) is the necessary condition of successful project development.

- Equipment. For today satisfactory, for real development project-needs a sharp increase.

- Materials - exceptionally poor supply. Difficult to foresee beforehand the needed parameters. Relatively small needed amount. Necessity in out of order supply.

- Salary system - lower rates than in SCB 245 (Special Design Bureau No 245 of Moscow with its "Strela" computer - BESM competitor) - as a result, the difficulties with hiring of engineers and technical assistance personnel.

Project expectations (page № 85 of Lebedev's notebook).

- Model launching in the $4^{\text {th }}$ quarter of 1950. Possibility to solve real problems.

- Hazard to wreck the successful completion of preliminary project draft.

○ The need of immediate start of building the experimental model. 
- Having the needed supply it is possible to build the machine by the second half of 1952.

The list of note titles itself shows that Lebedev was doing his design work very carefully, trying to understand all the minutest details, many of which were discovered by the scientist for the first time. He also tried not to forget the importance of perfect project organization and planning. Lebedev himself wrote the BESM project plan, which was identified by V.B. Karpova. This plan was found among the documents in the IPMCE archive storage. Lebedev permanently controlled the progress (Figure 10). According to this plan, the preliminary project draft should have been finished by the end of the first quarter of 1951 (approximately the same time with the completion of MESM model). The plan designated three main work directions:

1. Cells principle schemes design.

2. Mathematical and experimental testing.

3. Preliminary project draft development.

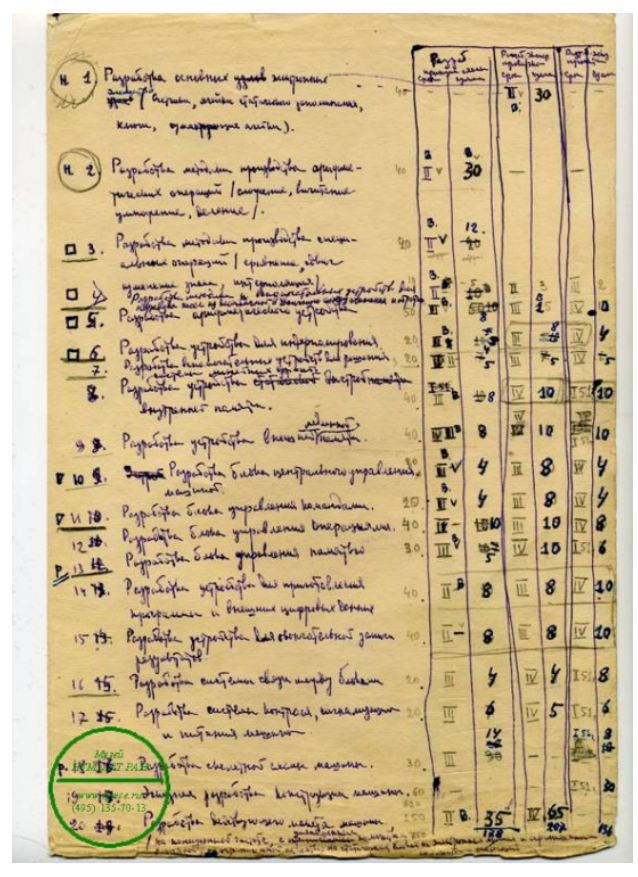

Fig. 10. BESM preliminary project draft plan handwritten by Lebedev in 1950

For each plan direction twenty basic items were defined, for which the dates and resources were fixed. Those basic works were the following:

1. Development of the basic electronic elements (counters, cells of static storage, keys, accumulators). 
2. Development of the methods of producing the arithmetic operations (addition, subtraction, multiplication, division).

3. Development of the methods of producing the special operations (comparison, shift, negation, interpolation).

4. Development of the methods and auxiliary devices for converting numbers from decimal to binary system and backward.

5. Development of the arithmetic unit.

6. Development of the unit for interpolation.

7. Development of the auxiliary units for solving the system of linear equations.

8. Development of the fast internal memory unit.

9. Development of the external memory unit.

10. Development of the central controlling unit of the machine.

11. Development of the instruction management unit.

12. Development of the operation management unit.

13. Development of the memory management unit.

14. Development of the unit for program and external digital data preparing.

15. Development of the unit for final result storing.

16. Development of the inter-unit link system.

17. Development of the monitoring, signaling and power supply system.

18. Development of the overall computer scheme.

19. Development of the computer design and construction.

20. Development of the computer working model (using the decreased frequency, decreased number of bits, restricted memory size, built on static electronic tubes and with restricted number of operations).

\section{From MESM to BESM}

The plan was written not for Lebedev alone. By the spring of 1951, nearly fifty engineers have been working in the IPMCE Laboratory No 1. There were experienced employees such as L.A. Lubovitch and K.S. Nesloukhovsky on his team, as well as very young people and future academicians such as V.S. Bourtsev and V.A. Melnikov. The future IPMCE chief designers V.N. Laut and P.P. Golovistikov (who at 27 years of age was four years older than others were) and some other very successful IPMCE collaborators were also among them. Young colleagues of Lebedev who simultaneously monitored two fundamental projects of MESM and BESM, were very helpful for him and his work.

The changes can be seen on the plan. Sometimes the initial dates were shifted, but some of them were later restored. Still the preliminary project draft was completed just during the first quarter of 1951. It was very important for Lebedev to run his both projects without hindering each other. In the very beginning of 1951, the MESM presentation to the state commission took place. On the $21^{\text {st }}$ of Aprilof 1951 the state commission on BESM project draft started its work. By the end of December 1951 MESM operated in its new design and in summer of 1952, the BESM manufacturing was completed. It was in operation by the autumn of 1952 . 
The work on BESM was not an easy one. The Special Design Bureau 245 was working on its own computer called the "Strela" (meaning "Arrow") in parallel and in certain circumstances only one computer (BESM or "Strela") could be chosen for serial production. The traces of scientific and technical competition can be seen in Lebedev's notebook (see page 84 of Figure 8). As a result, in April 1953 the State Commission with its chairman M.V. Keldysh approved the successful completion of BESM development. Since June 1953 Lebedev had started his work as the IPMCE director. Now this institute is named after him.

On $23^{\text {rd }}$ of October 1953 Lebedev was elected a member of the AS USSR within the Division of Physics and mathematics. He was the first academician with specialization "calculating devices". In 1954 he was rewarded by the USSR government highest award for creating the BESM computer and in 1956 he was given the USSR highest honorable title "Hero of Socialist Labour".

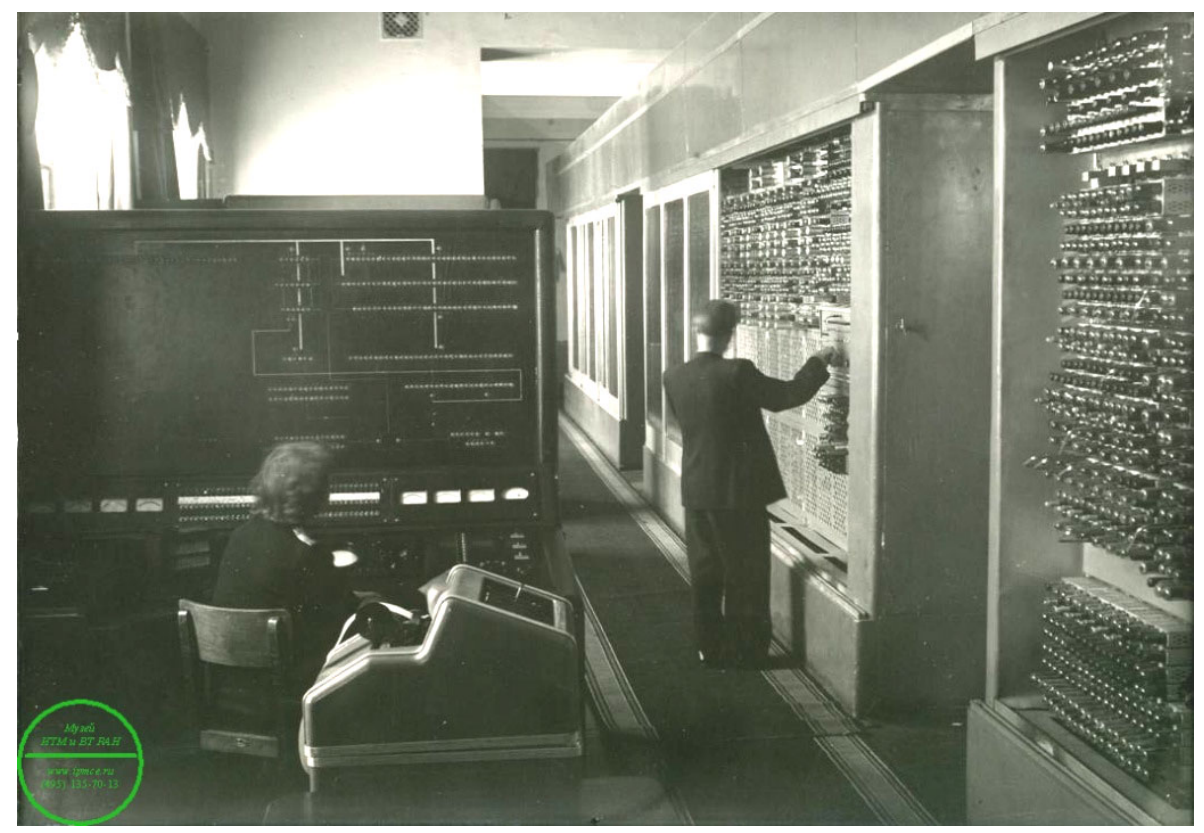

Fig. 11. BESM-1 computer on the ground floor of IPMCE building in Moscow

Many problems earlier seemed to be unsolvable, because of the large amount of calculations, were easily solved using BESM. Lebedev himself liked the example of calculating the artillery shell flight trajectory. With BESM, this calculation was faster than the shell itself. 


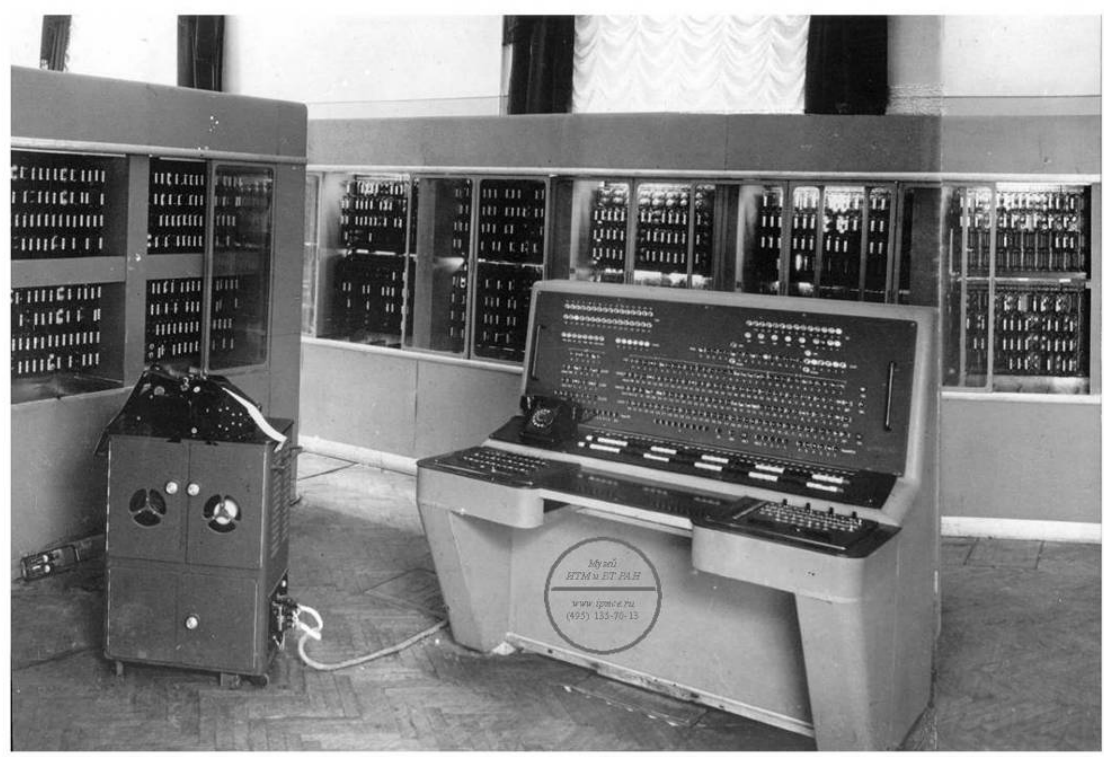

Fig. 12. Serial version of the BESM computer that was named BESM-2

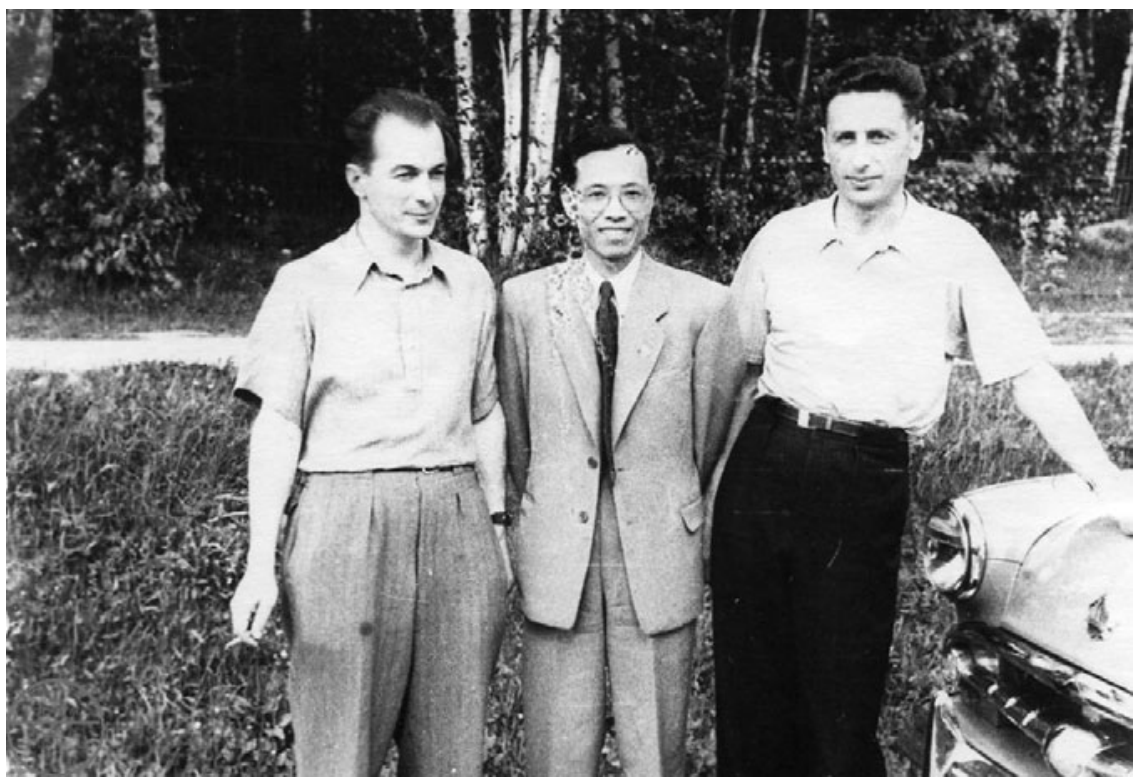

Fig. 13. O.K. Shcherbakov (to the right) and A.A. Pavlikov together with the member of Chinese group in IPMCE 
The first BESM (Figure 11) was installed on the ground floor of the IPMCE building in Moscow. For the long time it was solving both scientific/theoretical and application problems (some of them were described in Lebedev's article in [3]). In particular, this computer was used for calculating the trajectory of the rocket that brought the USSR emblem to the Moon.

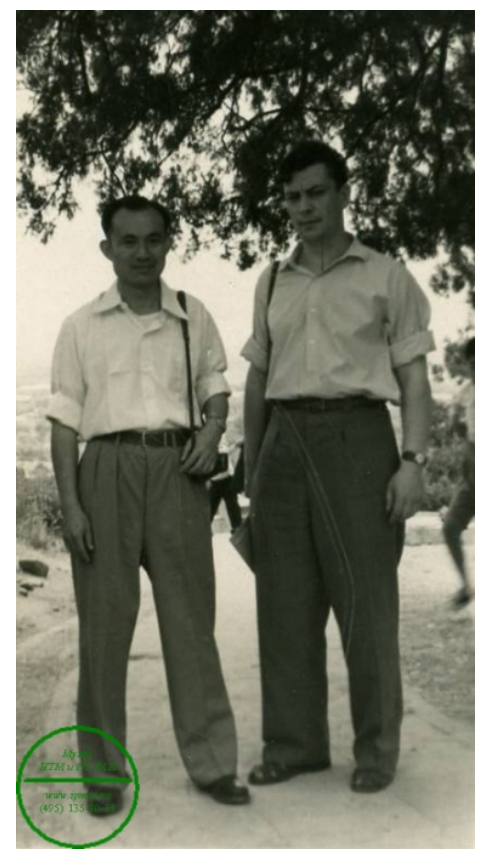

Fig. 14. V.A. Melnikov (to the right) during his business trip to China

After establishing of the Computing Centre at the AS USSR in 1955, the new task had to be performed by IPMCE: to prepare BESM computer for mass production. That was done by the end of 1957, when a factory in Ulyanovsk (a city on river Volga) started to manufacture the computer named BESM-2 (Figure 12). These computers were installed in almost all computing centers of the country. BESM-2 was used for calculating the data for the Earth satellites launching and for the first manned space ships.

BESM-2 was reproduced in China with the help of IPMCE team of engineers headed by Oleg Shcherbakov [2]. V.A. Melnikov also visited China. Five IPMCE collaborators were given state awards of the Chinese People's Republic. There are several pictures with IPMCE engineers and their Chinese colleagues in the IPMCE museum (Figures 13 and 14).

In October 1955, Lebedev made his report at the International Conference for electronic calculating machines in Darmstadt (West Germany). That was a real sensation: BESM appeared to be the fastest computer in Europe. The future would have shown 
that all the computers of the BESM series (from the first BESM to BESM-6) were the best universal computers in Europe for the moment of their first appearance.

Getting such powerful instrument as BESM for complicated mathematical calculations did not stop development of new computers. By that time, Lebedev could clearly see the important role of computers in the state scientific and economic progress. By the moment of BESM's completion Lebedev had already thought over the principles and architecture of a new computer - M-20 that should have become the fastest computer in the world (its performance was about 20000 instructions per second). Many new logical operations were implemented in M-20 such as address modifications, operation combinations, and hardware loop support.

Besides general applications Lebedev made a great contribution in another computer implementation field - controlling objects in a real time mode. For his colleagues and the future IPMCE director V.S. Bourtsev (Figure 15) among them, Lebedev formulated the task of building small computers "Diana-1" and "Diana-2", that were intended for using in the systems of directing a fighter to its targets[1].

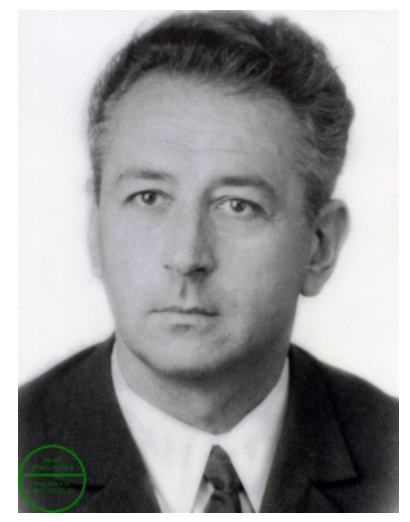

Fig. 15. V.S. Bourtsev

Yesterday's students soon became famous scientists who carried on the development of new computers. Academician V.S. Bourtsev started his carrier in IPMCE with designing the BESM instruction management unit. He continued with taking part in the design of a series of "Diana" computers, which were followed by the M-40, M-50, 5E92b, 5E51, 5E26 and the "Elbrus" series. The first work of (future) academician V.A. Melnikov started with BESM operation management unit, later he continued it with BESM-2, BESM-6, and the AS-6.

In the IPMCE museum, there is a model of one of the BESM-1 sections (Figure 16), which is a real monument to science and engineering. This model represents original units, cells and separate fragments of BESM-1 and BESM-2 that remained intact since the beginning of 1950s.

The value of BESM computer for Russian and world computer engineering can hardly be overestimated. Many of that, what was first tested in process of this computer design, is an ordinary ("classical”) thing now [4,6,7]. 


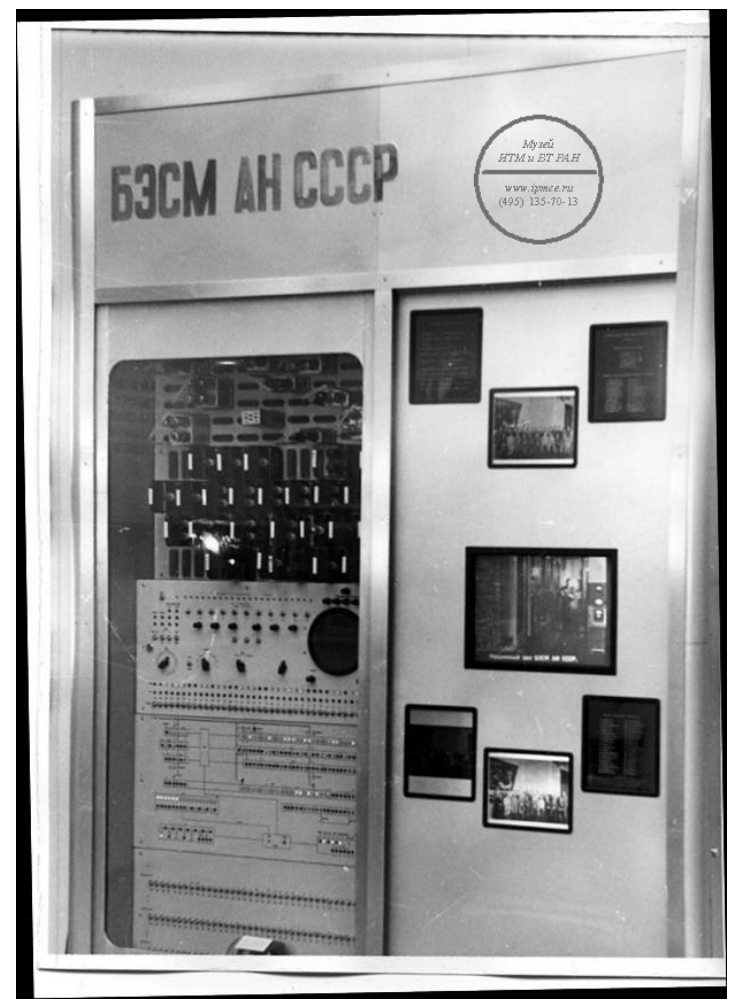

Fig. 16. Model of BESM-1 computer in the IPMCE history museum

\section{References}

[1] Bourtsev, V.S. (ed.): Sergey Lebedev. 100 years since birthday of the founder of domestic electronic computers. FizMatLit, Moscow (2002)

[2] Lebedev, S.A.: The creator of domestically produced computers, 2nd edn., Institute for Precise Mechanics and Computer Engineering (1990/2002)

[3] Lebedev, S.A.: Electronic Calculating Machine, Pravda newspaper, Moscow (December 4, 1955)

[4] Lebedev Institute of Precision Mechanics and Computer Engineering, Russian Academy of Sciences (IPMCE), http: / / www . ipmce.ru/

[5] Malinovsky, B.: Store Eternally. Gorobetz, Kiev (2007) ISBN 978-966-96940-0-3

[6] Museum of the USSR Computers History, http://www.bashedu.ru/konkurs/tarhov/english/index_e.htm

[7] Russian Virtual Computer Museum, http: / / www. computer-museum.ru/english/index.php

[8] Ryabov, G.G. (ed.): From BESM to supercomputer. Notes on history of Lebedev's IPMCE by his colleagues. Institute for Precise Mechanics and Computer Engineering, in 2 volumes (1988)

[9] Zhdanov, P.S., Lebedev, S.A.: Stability of parallel functioning of electrical systems, 2nd edn., pp. 263-387. EnergoIzdat, Moscow (1933/1934) 